\title{
Cannabinoids and COVID-19
}

\author{
Myriam El Biali ${ }^{a}$ Barbara Broers $^{b} \quad$ Marie Besson $^{a} \quad$ Jules Demeules ${ }^{a}$ \\ a Division of Clinical Pharmacology and Toxicology, Geneva University Hospitals, Geneva, Switzerland;

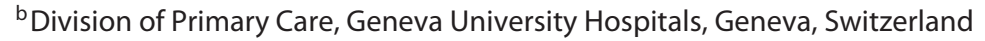

\section{Keywords}

SARS-CoV-2 · COVID-19 · Immunity · Cannabinoids ·

Endocannabinoid system

\begin{abstract}
Since the endocannabinoid system is involved in immune function, the effect of cannabinoid intake on infectious conditions is questioned for several years and is of particular interest in the COVID 19 pandemia. Some data suggest that the immunomodulatory effect of cannabinoids may affect the course and severity of SARS-CoV-2 infection. Given the large number of cannabinoids consumers in the community, this commentary presents the current knowledge on the potential impact of cannabinoids and endocannabinoids on bacterial and viral infection courses namely SARS-CoV-2 disease. Practical recommendations, which can be drawn from the literature, are given. $\quad$ (2020 The Author(s)

Published by S. Karger AG, Basel
\end{abstract}

\section{Introduction}

Since the end of the year 2019, the world is confronted with a new epidemic, later pandemic, due to a previously unidentified coronavirus, SARS-CoV-2, resulting in a wide range of clinical, mainly respiratory manifestations, called coronavirus disease 2019 (COVID-19). This infection can lead to severe complications and is associated

karger@karger.com www.karger.com $/ \mathrm{mca}$

Karger $\stackrel{\text { ' }}{5}$

GOPEN ACCESS
(C) 2020 The Author(s)

Published by S. Karger AG, Basel

This article is licensed under the Creative Commons AttributionNonCommercial-NoDerivatives 4.0 International License (CC BYNC-ND) (http://www.karger.com/Services/OpenAccessLicense). Usage and distribution for commercial purposes as well as any distribution of modified material requires written permission. with a significant mortality rate, especially in the elderly and those with comorbid disorders. However, sometimes fatal complications can also arise in apparently healthy persons, and there is an urgent need to understand the role of immune reactions in this new disease. Indeed, while immune responses, especially the innate part, is vital for the control and resolution of coronavirus infections, and loss of control can lead to immunopathogenesis. Acute inflammatory reactions and cytokine storms have been ascribed a possible role in critically ill COVID-19 patients by a number of studies showing elevated plasma levels of many cytokines and chemokines in patients with COVID-19 [1-4].

A possible association between nonsteroidal antiinflammatory drug (NSAID) use and worsening of viral or bacterial infection was raised by the French Minister. He based his warning on a detailed report of the French pharmacovigilance authorities ANSM 2018. The recommendation to limit NSAID use during SARS-CoV-2 infection was then widely adopted.

Based on in vitro data, it was suggested that one of the mechanisms involved in the worsening of NSAID infection could be related to inhibition of fatty acid amide hydrolase (FAAH) by NSAIDs. Yet, FAAH is the enzyme responsible for the degradation of anandamide (AEA), one of the main mediators of the endocannabinoid (EC) system (ECS) and a possible key player in the worsening of bacterial infections - particularly during sepsis [5]. 
The question, therefore, arises whether AEA and ECS increase the severity of viral or bacterial infections, and whether the consumption of cannabis or cannabis derivatives/synthetic products could influence this risk. In this commentary, we address the question of the potential impact of cannabinoids on COVID-19 severity.

\section{Organization of the ECS}

The ECS is composed of EC, enzymes for EC synthesis and degradation, including FAAH, and their targets cannabinoid receptor 1 (CB1) and cannabinoid receptor 2 (CB2), which are widely distributed in the body. CB1 is mainly located in the central nervous system (CNS), whereas CB2 is rather expressed outside the CNS, namely in the immune system. Cannabinoid receptors are activated by different ligands, which can either be endogenous, such as ECs (lipids derived from arachidonic acid), or exogenous, such as phytocannabinoids (present in Cannabis sativa L. and derived products) or synthetic compounds [6]. The most studied ECs are AEA and 2-arachidonoylglycerol (2-AG). More than 100 phytocannabinoids have been identified in C. sativa L. [7], the main psychoactive component of which is $\Delta^{9}$-tetrahydrocannabinol (THC). Another major phytocannabinoid component of $C$. sativa L. quantitatively speaking is cannabidiol (CBD), which is regarded as nonpsychotropic. Arachidonyl-2-chloroethanolamide (ACEA) is a synthetic cannabinoid agonist [6].

Among the numerous phytocannabinoids described, some have a known mechanism of action involving ECS. For example, THC is a partial CB1 and CB2 agonist [8]. Cannabinol is a partial CB2 agonist and a weak CB1 agonist $[9,10]$. Cannabigerol and cannabichromene inhibit the reuptake of AEA $[9,11]$. CBD is a noncompetitive negative allosteric modulator of CB1, i.e., it lowers the affinity of THC and 2-AG for CB1 [12]. In addition, it inhibits the uptake and metabolism of AEA [13]. The precise mechanism of action of many phytocannabinoids, such as cannabivarin, cannabinodiol, or cannabielsoin on ECS is not yet fully understood [10].

\section{Link between ECs and the Immune System}

The wide expression of $\mathrm{CB} 2$ in the immune system and to a lesser extent CB1 suggests that cannabinoid receptors, once activated, may be involved in immune system functions [14]. In addition, AEA and 2-AG can modulate inflammation without necessarily binding to their receptors owing to their arachidonic acid-containing structure, which make them precursors of anti-inflammatory lipids [6].

According to a number of experimental studies in rodents, activation of CB1 is crucial for the development of an effective innate immune response during bacterial infection, while activation of CB2 prevents further inflammation-related damage during sepsis by an immunosuppressive effect [6]. For instance, a higher mortality and higher concentrations of pro-inflammatory cytokines (TNF- $\alpha$ and IL-6) are observed in sepsis in non-CB2-expressing mice compared to controls [15]. It has thus been postulated that the ECS could be used as a potential therapeutic target for the treatment of sepsis [6]. Its activation could also avoid organ damage due to excess inflammation, particularly in the lungs, which are among the most vulnerable organs in sepsis [16]. Indeed, activation of CB2 decreases septic lung lesions in mice by promoting autophagy and by inhibiting the release of inflammatory mediators [16]. In addition, in vitro, selective activation of CB2 has been shown to modulate monocyte migration $[17,18]$ and to inhibit TNF- $\alpha$ in a dose-dependent manner [18]. It may play a role in chronic inflammatory diseases such as rheumatoid arthritis [17] or multiple sclerosis [18].

In case of viral infections, such as human immunodeficiency virus (HIV) or Theiler virus (a murine virus of the picornavirus family), in vitro and in vivo studies showed suppression of proinflammatory cytokines and an increase in anti-inflammatory cytokines related to AEA and 2 -AG $[6,19,20]$. In a mouse model of respiratory syncytial virus (RSV) infection, CB2 activation reduced the signs of infection by modulating the immune system [21]. In mice, the administration of a CB1 agonist reduced pulmonary complications in case of RSV infection, whereas the administration of a CB1 antagonist led to an accumulation of immune cells in the peribronchial and perivascular spaces compared to the control group [22].

In humans, few studies have examined possible associations between ECS and immune responses. For example, a genetic polymorphism in CB2 (CBQ63R), a common missense mutation that reduces maximum EC-induced responses of CB2 [15], has been associated with an increased risk of hospitalization in young children infected with RSV $(n=83)$, with a 2 -fold significantly increased risk of developing severe acute respiratory tract infection in children carrying the $\mathrm{Q}$ allele $(\mathrm{OR}=2.148 ; 95 \% \mathrm{CI}$ : 1.09-4.22) and a 3-fold significantly increased risk of QQ genotype carriers $(\mathrm{OR}=3.28$; 95\% CI: $1.22-8.71)$ [21]. 


\section{Effect of Cannabinoids and Cannabis on the Immune System}

CBD inhibits the migration of murine macrophages in vitro and in vivo by activating CB2 in a dose-dependent manner [23]. Numerous in vitro and in vivo studies, conducted on animal and human cells, suggested that CBD has immunosuppressive and anti-inflammatory properties due either to direct inhibition of microglial, innate, and $\mathrm{T}$ cells, or by inducing apoptosis of regulatory $\mathrm{T}$ cells or myeloid-derived suppressor cells [24]. Among other mechanisms, immune system modulation of $\mathrm{CBD}$ is thought to be mediated through activation of TRPV1 [24], regulation of FAAH, and indirect action on CB1 [25]. However, the administration of phytocannabinoids in experimental models revealed conflicting results. In the 1970s, experimental studies in rodents showed greater lethality of bacterial endotoxins with an additive toxicity when co-administered with very high THC dosages [26]. In contrast, more recent in vitro and animal studies suggest that extracts of $C$. sativa have bactericidal activity on gram-positive and gram-negative bacteria and certain fungi $[6,27]$.

Long-term daily use of cannabis has been associated with fibrosis progression in cases of hepatitis C [28]. Arachidonyl-2-chloroethanolamide, a relatively selective agonist of $\mathrm{CB} 1$, leads to facilitation of hepatitis $\mathrm{C}$ viral replication in hepatocyte cultures in vitro in association with $\mathrm{CB} 1$ overexpression and higher 2-AG levels [29]. Concerning THC, it has been associated with the presence of increased extracellular herpes simplex virus in vitro $[30,31]$ and an increased mortality in mice [32] and guinea pigs [33] with vaginal herpes simplex virus infection. THC has also been associated with increased HIV replication and influenza virus load in animal models.

In humans, cannabis use is not associated with a reduction in peripheral CD4 counts or loss of HIV control in cross-sectional studies [34]. A pilot study conducted on healthy volunteers $(n=10)$ revealed that a single dose of $30 \mathrm{mg}$ of water-soluble or lipid-soluble CBD significantly reduced the TNF level in peripheral blood mononuclear cells stimulated with bacterial lipopolysaccharide $90 \mathrm{~min}$ after administration. This was not the case in nonstimulated cells or for IL-10 production [35]. In a double-blind, placebo-controlled trial, 14-week oral treatment with CBD $(20 \mathrm{mg} / \mathrm{kg} /$ day $)$ for drug-resistant seizures in 120 children and young adults with the Dravet syndrome resulted in a nonsignificant increase in upper respiratory tract infections and pyrexia in the $\mathrm{CBD}$ group compared to the placebo group (11 vs. 8 and 15 vs. $8 \%$, respectively) [36]. In another double-blind placebo-controlled trial in patients with the Dravet syndrome $(n=$ 190 ), the CBD group (oral CBD solutions of 10 or $20 \mathrm{mg} /$ $\mathrm{kg}$ /day) demonstrated pyrexia in $22-23 \%$ of patients compared to $17 \%$ of patients receiving placebo [37]. Finally, the use of add-on $(20 \mathrm{mg} / \mathrm{kg})$ oral CBD daily in patients with seizures associated with the LennoxGastaut syndrome for 14 weeks was associated with viral infections (pneumonia: $n=4$ ) almost exclusively by subjects with concomitant use of clobazam while no cases were reported in the placebo group [38]. Still, the assumption was made that this could be the result of a CBD-clobazam interaction promoting somnolence and broncho-aspirations and not necessarily an impact of CBD on immunity [39].

\section{The Role of ECS, Cannabinoids, and Cannabis in SARS-CoV-2 Infection}

To date, no scientific studies have evaluated the role of EC, cannabinoids, and cannabis in the evolution of SARSCoV-2 infection. Also, no epidemiological data are available on the incidence of COVID-19 in persons taking medical or nonmedical cannabinoids.

In the French government's recommendations concerning COVID-19, the consumption of inhaled cannabis products was mentioned as potentially promoting the onset of coughing and thus increasing transmission of the virus, particularly in the case of asymptomatic infections, as well as in intensifying COVID-19 respiratory symptoms. In addition, cannabis can alter the vigilance level and thus may aggravate central symptoms of COVID-19, such as fatigue and confusion [40].

Recent rumors suggested a positive impact of nicotine (smoked sometimes in combination with cannabis) on COVID-19 [41]. These findings are debated and should be confirmed by clinical studies [42, 43], but could represent a potential confounder in the relation between cannabis and COVID-19.

\section{Conclusion}

ECS has a modulating effect on the immune system, but people taking cannabinoids or cannabis are not considered immunosuppressed. No studies are currently available on the incidence and course of SARS-CoV-2 infection (COVID-19) in persons taking cannabinoids. 
Preexisting nonmedical consumption of cannabinoids should not be increased, rather decreased, for the duration of the COVID-19 pandemic considering the potential respiratory complications. Sharing a joint should be avoided since this might be a potential way of transmitting the virus. Also, "over-the-counter" CBD cannot be recommended since the impact on immunity in case of SARS-CoV-2 infection is not clear.

Continuation or discontinuation of therapeutically prescribed cannabinoids should be discussed on a caseby-case basis with the prescribing physician taking each patient's individual risk-benefit ratio into account.

Given the large-scale, worldwide consumption of cannabinoids, either medical or not, it appears crucial to improve preclinical and clinical knowledge on cannabinoids and COVID- 19.

In order to confirm an immunomodulatory effect of cannabinoids and a potential interaction with SARS$\mathrm{CoV}-2$, in vitro and in vivo experimental models are requested. From a clinical point of view, epidemiological studies (with case-control design) and retrospective data about the consumption of cannabinoids by patients with SARS-CoV-2 infection are needed in order to suggest a potential influence of cannabinoids on disease progression and severity. Such studies should pave the way for a more accurate assessment of the risk-benefit balance. In the absence of safety issues and in case of potential experimental positive targets, corresponding randomized prospective early phase 2 studies should confirm a possible benefit in well-designed trials.

\section{Conflict of Interest Statement}

The authors have no conflicts of interest to declare. This commentary is based on an internal clinical guideline, available in French under: http://www.intrahug.ch/sites/intranet/files/structures/directions/communication/Coronavirus-COVID19/Recommandations-Institutionnelles/cannabinoides_et_covid-19.pdf.

\section{Funding Sources}

No funding was obtained for this study.

\section{Author Contributions}

The first and last author (Myriam El Biali, Jules Desmeules) did most of the literature research and wrote the clinical guideline in French. Myriam El Biali provided the first English version of the article. Barbara Broers and Marie Besson completed the guideline and the article.

\section{References}

1 Guo YR, Cao QD, Hong ZS, Tan YY, Chen $\mathrm{SD}$, Jin HJ, et al. The origin, transmission and clinical therapies on coronavirus disease 2019 (COVID-19) outbreak - an update on the status. Mil Med Res. 2020 Mar;7(1):11.

2 Huang C, Wang Y, Li X, Ren L, Zhao J, Hu Y, et al. Clinical features of patients infected with 2019 novel coronavirus in Wuhan, China. Lancet. 2020 Feb;395(10223):497-506.

3 Chen C, Zhang XR, Ju ZY, He WF. [Advances in the research of mechanism and related cytokine storm induced by coronavirus disease 2019]. Zhonghua Shao Shang Za Zhi. 2020; 36(6):471-5.

4 Tian S, Hu W, Niu L, Liu H, Xu H, Xiao SY. Pulmonary pathology of early-phase 2019 novel coronavirus (COVID-19) pneumonia in two patients with lung cancer. J Thorac Oncol. 2020 May;15(5):700-4.

5 RAPPORT D'EXPERTISE: INFECTIONS BACTERIENNES GRAVES (de la peau et des tissus mous, pleuro-pulmonaires, neurologiques et ORL) rapportées avec l'ibuprofene ou le ketoprofene dans le traitement symptomatique de la fièvre ou de douleur non rhumatologique. Marseille: CRPV Tours - CRPV Marseille; 2019 Mars 3.

6 Hernández-Cervantes R, Mendez-Diaz M, Prospero-Garcia O, Morales-Montor J. Im- munoregulatory role of cannabinoids during infectious disease. Neuroimmunomodulation. 2017;24(4-5):183-99.

7 Hanuš LO, Meyer SM, Muñoz E, TaglialatelaScafati O, Appendino G. Phytocannabinoids: a unified critical inventory. Nat Prod Rep. 2016 Nov;33(12):1357-92.

8 Pertwee RG. Pharmacological actions of cannabinoids. Handb Exp Pharmacol. 2005; (168): 1-51.

9 Pisanti S, Malfitano AM, Ciaglia E, Lamberti A, Ranieri R, Cuomo G, et al. Cannabidiol: state of the art and new challenges for therapeutic applications. Pharmacol Ther. 2017 Jul;175:133-50.

10 Morales P, Hurst DP, Reggio PH. Molecular targets of the phytocannabinoids: a complex picture. Prog Chem Org Nat Prod. 2017;103: 103-31.

11 De Petrocellis L, Ligresti A, Moriello AS, Allarà $\mathrm{M}$, Bisogno $\mathrm{T}$, Petrosino $\mathrm{S}$, et al. Effects of cannabinoids and cannabinoidenriched Cannabis extracts on TRP channels and endocannabinoid metabolic enzymes. Br J Pharmacol. 2011 Aug;163(7): 1479-94.

12 Laprairie RB, Bagher AM, Kelly ME, DenovanWright EM. Cannabidiol is a negative allosteric modulator of the cannabinoid CB1 recep- tor. Br J Pharmacol. 2015 Oct;172(20):4790805.

13 McPartland JM, Duncan M, Di Marzo V, Pertwee RG. Are cannabidiol and $\Delta(9)$-tetrahydrocannabivarin negative modulators of the endocannabinoid system? A systematic review. Br J Pharmacol. 2015 Feb;172(3):73753.

14 Rieder SA, Chauhan A, Singh U, Nagarkatti M, Nagarkatti P. Cannabinoid-induced apoptosis in immune cells as a pathway to immunosuppression. Immunobiology. 2010 Aug; 215(8):598-605.

15 Gui H, Sun Y, Luo ZM, Su DF, Dai SM, Liu X. Cannabinoid receptor 2 protects against acute experimental sepsis in mice. Mediators Inflamm. 2013;2013:741303.

16 Liu AP, Yuan QH, Zhang B, Yang L, He QW, Chen $\mathrm{K}$, et al. Cannabinoid receptor 2 activation alleviates septic lung injury by promoting autophagy via inhibition of inflammatory mediator release. Cell Signal. 2020 May;69: 109556.

17 Montecucco F, Burger F, Mach F, Steffens S. CB2 cannabinoid receptor agonist JWH-015 modulates human monocyte migration through defined intracellular signaling pathways. Am J Physiol Heart Circ Physiol. 2008 Mar;294(3):H1145-55. 
18 Malfitano AM, Laezza C, Bertini S, Marasco $\mathrm{D}$, Tuccinardi $\mathrm{T}$, Bifulco $\mathrm{M}$, et al. Immunomodulatory properties of 1,2-dihydro-4-hydroxy-2-oxo-1,8-naphthyridine-3-carboxamide derivative VL15. Biochimie. 2017 Apr; 135:173-80.

19 Mestre L, Iñigo PM, Mecha M, Correa FG, Hernangómez-Herrero $\mathrm{M}$, Loría $\mathrm{F}$, et al. Anandamide inhibits Theiler's virus induced VCAM-1 in brain endothelial cells and reduces leukocyte transmigration in a model of blood brain barrier by activation of $\mathrm{CB}(1)$ receptors. J Neuroinflammation. 2011 Aug; 8(1):102.

20 Krishnan G, Chatterjee N. Endocannabinoids affect innate immunity of Muller glia during HIV-1 Tat cytotoxicity. Mol Cell Neurosci. 2014 Mar;59:10-23.

21 Tahamtan A, Samieipoor Y, Nayeri FS, Rahbarimanesh AA, Izadi A, Rashidi-Nezhad A, et al. Effects of cannabinoid receptor type 2 in respiratory syncytial virus infection in human subjects and mice. Virulence. 2018 Jan;9(1): 217-30.

22 Tahamtan A, Tavakoli-Yaraki M, Shadab A, Rezaei F, Marashi SM, Shokri F, et al. The role of cannabinoid receptor 1 in the immunopathology of respiratory syncytial virus. Viral Immunol. 2018 May;31(4):292-8.

23 Sacerdote P, Martucci C, Vaccani A, Bariselli F, Panerai AE, Colombo A, et al. The nonpsychoactive component of marijuana cannabidiol modulates chemotaxis and IL-10 and IL12 production of murine macrophages both in vivo and in vitro. J Neuroimmunol. 2005 Feb;159(1-2):97-105.

24 Nichols JM, Kaplan BL. Immune responses regulated by cannabidiol. Cannabis Cannabinoid Res. 2020 Feb;5(1):12-31.

25 de Filippis D, Iuvone T, d'amico A, Esposito G, Steardo L, Herman AG, et al. Effect of cannabidiol on sepsis-induced motility disturbances in mice: involvement of CB receptors and fatty acid amide hydrolase. Neurogastroenterol Motil. 2008 Aug;20(8):919-27.
26 Bradley SG, Munson AE, Dewey WL, Harris LS. Enhanced susceptibility of mice to combinations of delta 9-tetrahydrocannabinol and live or killed gram-negative bacteria. Infect Immun. 1977 Aug;17(2):325-9.

27 Farha MA, El-Halfawy OM, Gale RT, MacNair CR, Carfrae LA, Zhang X, et al. Uncovering the hidden antibiotic potential of cannabis. ACS Infect Dis. 2020 Mar;6(3):338-46.

28 Hézode C, Roudot-Thoraval F, Nguyen S, Grenard P, Julien B, Zafrani ES, et al. Daily cannabis smoking as a risk factor for progression of fibrosis in chronic hepatitis C. Hepatology. 2005 Jul;42(1):63-71. Erratum: Hepatology. 2005 Aug;42(2):506.

$29 \mathrm{Lu} \mathrm{T}$, Newton C, Perkins I, Friedman H, Klein TW. Role of cannabinoid receptors in delta9-tetrahydrocannabinol suppression of IL12 p40 in mouse bone marrow-derived dendritic cells infected with Legionella pneumophila. Eur J Pharmacol. 2006;532(1-2): 170-7.

30 Cabral GA, McNerney PJ, Mishkin EM. Delta-9-tetrahydrocannabinol enhances release of herpes simplex virus type 2. J Gen Virol. 1986 Sep;67(Pt 9):2017-22.

31 Cabral GA, McNerney PJ, Mishkin EM. Effect of micromolar concentrations of delta-9-tetrahydrocannabinol on herpes simplex virus type 2 replication in vitro. J Toxicol Environ Health. 1987;21(3):277-93.

32 Mishkin EM, Cabral GA. delta-9-Tetrahydrocannabinol decreases host resistance to herpes simplex virus type 2 vaginal infection in the B6C3F1 mouse. J Gen Virol. 1985 Dec; 66(Pt 12):2539-49.

33 Cabral GA, Mishkin EM, Marciano-Cabral F, Coleman P, Harris L, Munson AE. Effect of delta 9-tetrahydrocannabinol on herpes simplex virus type 2 vaginal infection in the guinea pig. Proc Soc Exp Biol Med. 1986 Jun; 182(2):181-6.

34 Costiniuk CT, Jenabian MA. Cannabinoids and inflammation: implications for people living with HIV. AIDS. 2019 Dec;33(15): 2273-88.
35 Hobbs JM, Vazquez AR, Remijan ND, Trotter RE, McMillan TV, Freedman KE, et al. Evaluation of pharmacokinetics and acute anti-inflammatory potential of two oral cannabidiol preparations in healthy adults. Phytother Res. 2020 Jul;34(7):1696-703.

36 Devinsky O, Cross JH, Laux L, Marsh E, Miller I, Nabbout R, et al; Cannabidiol in Dravet Syndrome Study Group. Trial of cannabidiol for drug-resistant seizures in the Dravet syndrome. N Engl J Med. 2017 May;376(21):2011-20.

37 Miller I, Scheffer IE, Gunning B, SanchezCarpintero R, Gil-Nagel A, Perry MS, et al.; GWPCARE2 Study Group. Dose-Ranging Effect of Adjunctive Oral Cannabidiol vs Placebo on Convulsive Seizure Frequency in Dravet Syndrome: A Randomized Clinical Trial. JAMA Neurol. 2020 May;77(5):613-21.

38 Thiele EA, Marsh ED, French JA, Mazurkiewicz-Beldzinska M, Benbadis SR, Joshi C, et al.; GWPCARE4 Study Group. Cannabidiol in patients with seizures associated with Lennox-Gastaut syndrome (GWPCARE4): a randomised, double-blind, placebo-controlled phase 3 trial. Lancet. 2018 Mar;391(10125): 1085-96.

39 Dos Santos RG, Guimarães FS, Crippa JA, Hallak JE, Rossi GN, Rocha JM, et al. Serious adverse effects of cannabidiol (CBD): a review of randomized controlled trials. Expert Opin Drug Metab Toxicol. 2020 Jun;16(6):517-26.

40 Javelot H, Llorca PM, Drapier D, Fakra E, Hingray C, Meyer G, et al. [Informations on psychotropics and their adaptations for patients suffering from mental disorders in France during the SARS-CoV-2 epidemic]. Encephale. 2020 Jun;46(3S):S14-34. French.

41 Propper RE. Does cigarette smoking protect against SARS-CoV-2 infection? Nicotine Tob Res. 2020 Apr;ntaa073.

42 Vardavas CI, Nikitara K. COVID-19 and smoking: a systematic review of the evidence. Tob Induc Dis. 2020 Mar;18(March):20.

43 Berlin I, Thomas D, Le Faou AL, Cornuz J. COVID-19 and smoking. Nicotine Tob Res. 2020 Apr;ntaa059. 